\title{
Uncertainty and sensitivity analyses of operational errors in air handling units and unexpected user behavior for energy efficiency and thermal comfort
}

\author{
Lukas Lauss (iD) Andreas Meier • Thomas Auer (i)
}

Received: 16 July 2020 / Accepted: 15 December 2021/Published online: 5 January 2022

(C) The Author(s) 2022

\begin{abstract}
Resource scarcity and anthropogenic climate change require the reduction of performance gaps in existing buildings. In addition to unexpected user behavior, performance gaps are primarily caused by the technical gap due to operational errors in building technology. The main objective of this paper is to quantify model input uncertainty incorporating uncertain boundary conditions in terms of operational errors using thermo-dynamic building performance simulations and to identify the most relevant input parameters for the performance gaps in air conditioning systems by means of sensitivity analyses. Model input uncertainty is stochastically determined using Monte-Carlo Simulations to calculate the target values "primary energy demand" as well as "over- and under-temperature degree hours" for an office building. Selected parameters are simulated in a specific uncertainty and sensitivity analyses using the Sobol' and Jansen estimators, which distinguish between a direct influence on the target variables and interactions between the parameters. The methodology
\end{abstract}

Lukas Lauss and Andreas Meier contributed equally to this work and effort. The authors wish it to be known that, in their opinion, the first 2 authors should be regarded as joint First Authors.

L. Lauss $(\bowtie) \cdot$ A. Meier · T. Auer

Building Technology and Climate Responsive

Design, Technical University Munich, Arcisstraße 21,

80333 Munich, Germany

e-mail: lukas.lauss@tum.de requires a selection process, which is carried out as part of relative uncertainty and relative sensitivity analyses. Furthermore, the operational errors are compared with construction factors as well as building physics inputs and design parameters for building technology systems to show their reciprocal effects as part of a comprehensive investigation. The main findings of this paper are that operational errors in air conditioning systems play an essential role in decreasing energy efficiency and thermal comfort, but do not warrant the significance of certain construction factors as well as setpoints in building technology. Moreover, the impact of operational errors on thermal overheating of the building investigated is minor compared to other targets that cause greater model input uncertainty.

Keywords Building performance simulations · Performance gap · Office buildings · Operational errors $\cdot$ Air handling units $\cdot$ Uncertainty analyses · Sensitivity analyses $\cdot$ Sobol-Jansen estimators . Sobol' · User behavior · Energy efficiency · Thermal comfort

\section{Introduction}

Energy-efficient building management as well as building technology and its automation increase energy efficiency and reduce greenhouse gas emissions. In the building sector, however, the measured 
values for the primary energy demand (PED) often exceed the calculated values (Struck, 2014). The increasingly intensively discussed topic of the performance gaps in existing buildings emphasizes the difference between planning target values and measurements in the real operation of technical building equipment. The reasons for increased energy consumption can be found in building and plant technology as well as its automation and can result first from a change in the climate (ambient gap). Consequently, the climate data, such as outside air temperature, solar radiation, wind and shading by trees, used in planning do not correspond to the actual climate. Second, user gaps may arise due to change in presence time, comfort requirements, and unexpected user behavior during building operation (user gap). Third, performance gaps are also caused by standards and guidelines, based on assumptions and simplifications which are made during the design and planning process (norm gap). Finally, the construction work in connection with building services engineering or building physics as well as operational management can deviate from the planning process, which results in technical gaps and causes performance gaps. This discrepancy not only affects energy consumption but also reduces user comfort and increases greenhouse gas emissions (Mojic et al., 2018). If malfunctions are not eliminated before commissioning, system efficiency may be impaired. Following the energy efficiency goal in building operations will not met or only partially achieved.

According to the Swiss Federal Office of Energy, more than $60 \%$ of non-residential buildings do not meet their energy efficiency goals (Reimann \& Bühlmann, 2016). The two main reasons for these deviations in the calculated energy demand in the planning phase and the measured energy consumption during building operation are on the one hand the user behavior (e.g., higher room temperature in winter than expected) and on the other hand operational errors in building technology (e.g., simultaneous heating and cooling). An analysis of around 150 individual operational errors in demonstration buildings by the German Federal Ministry of Economics shows that a substantial number of errors are caused in part or entirely by the faulty building technology (Réhault \& Zehnle, 2019). Our research project (Auer \& Lauss, 2020) identified some irregularities and problems in the operation of air handling units (AHU) in non-residential buildings: under-/overrun of the defined operating time, deviation (too high/too low) of supply air temperature from setpoint and sticked bypass damper in the heat exchanger.

In this paper, an error is defined as a system or component operating in a way that adversely affects the thermal comfort of users in a building and/or the energy efficiency. The abovementioned research studies have shown that different errors occur in most ventilation and air conditioning systems. In this context, single errors such as an offset of temperature sensors, e.g., room air temperature, can occur. In contrast, several errors can occur simultaneously (e.g., simultaneous heating and cooling of the pre-heating and cooling coil in air handling units) and result in combinatorial effects, which are often greater than the sum of the individual errors. Errors can also be divided into slow (deterioration) ones (e.g., contamination of a heating or cooling register) and/or sudden ones (e.g., a defective fan) (Haves, 1997). In order to realistically model operational errors that represent real operation of systems engineering, an error database must be developed that covers potential error types (e.g., devices, sensors, and control sequences) (Li \& O'Neill, 2018). For more on operational errors, see (Auer \& Lauss, 2020; Fisch et al., 2007; Grob et al., 2002; Hyvärinen, 1996), and (Lauss et al., 2020) which were used as a basis to set up a compilation of operational errors in ventilation and air conditioning systems.

The main task of this paper is to quantify the effects of operational errors in air handling units as well as unexpected user behaviors in terms of energy efficiency and thermal comfort related performance gaps in existing buildings. Moreover, in this paper, the most relevant input parameters for the technical gaps in terms of the operation of AHUs and user behavior including their interactions with building technology are identified through sensitivity analyses with Sobol' and Jansen estimators.

\section{Methodology}

In the field of building performance simulations (BPS), different applications exist to define the uncertainty of input parameters. Burhenne distinguishes between model uncertainty, numerical uncertainty, and model input uncertainty (Burhenne, 2013). In this 
paper, the focus is on model input uncertainty which arises when one is not completely certain what distributions and/or parameters to use. An uncertainty analysis (UA) is understood as a comprehensive investigation of the simulation model input and quantifies the total uncertainty of the result of a model. While conventional thermo-dynamic building simulations usually determines only a single value (point simulation: without distributions for inputs), a UA can also provide information on the variance in the results. In order to determine the most influential parameters, initial results are compared with results of modified parameters. It is thus possible to determine the likelihood of exceeding or undershooting target values. Several methods can be used to carry out a UA (Cox \& Baybutt, 1981). In this paper, Monte-Carlo simulations (MCS) have been chosen to carry out the UA because they are commonly used in building performance simulations and the principal advantage of the MCS is its very general applicability due to the lack of restrictions in the nature of the relationship between input and output (Cox \& Baybutt, 1981). Every input variable in an MCS has a defined probability distribution. Samples from the probability distributions are selected and combined to form a sample matrix (pre-processing) that can be simulated and afterwards statistically evaluated (post-processing) (see Fig. 1).

The aim of our paper is to apply the described methodology with Monte-Carlo simulations and to identify the most relevant operational and user errors within a case study for partial air conditioning systems (PACS). User errors refer to improper user behaviors such as the long-term opening of a window in winter while a ventilation and air conditioning system is operating and heating the zones in the building. In addition, the parameters are compared to construction and building physics factors which have already been shown to be sensitive input parameters in other research dealing with constructional factors, but without regard to operational errors in building technology (Burhenne, 2013) (Hopfe \& Hensen, 2011) (Ioannou, 2015) (Brohus \& Heiselberg, 2009) (Corrado \& Mechri, 2009). Regarding input parameters, three different groups (A, B, C) are defined for greater clarity and divided as follows:

- Parameter group A: Operational and user errors in PACS

- Parameter group B: Significant construction as well as building physics factors and target values based on literature research (Burhenne, 2013) (Hopfe \& Hensen, 2011) (Ioannou, 2015) (Brohus \& Heiselberg, 2009) (Corrado \& Mechri, 2009)

- Parameter group C: Design parameters and planning foundations for building technology

The simulations are carried out in a multi-stage process, which is shown in Fig. 2. Significant parameters are simulated in the specific UA and specific sensitivity analyses (SA) using the Sobol' and Jansen estimators. The calculation method was

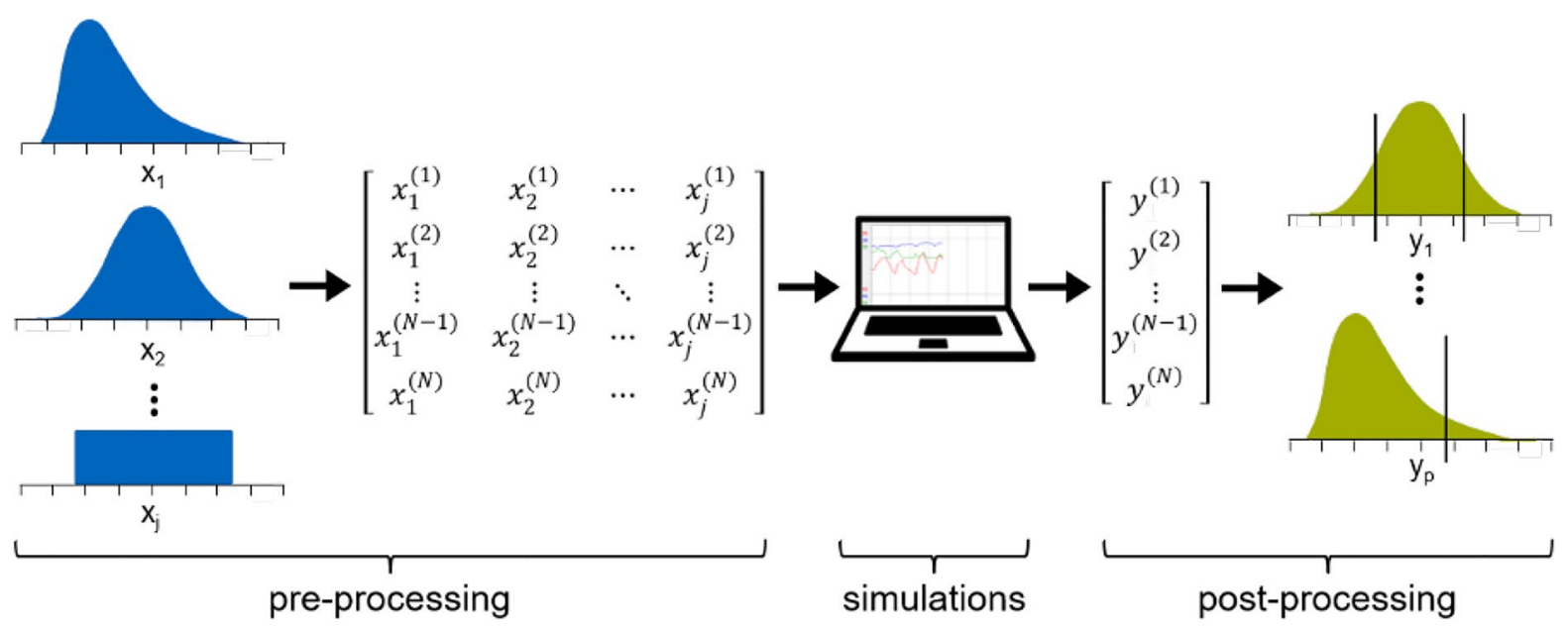

Fig. 1 Data generation of a MCS 
Fig. 2 Research methodology

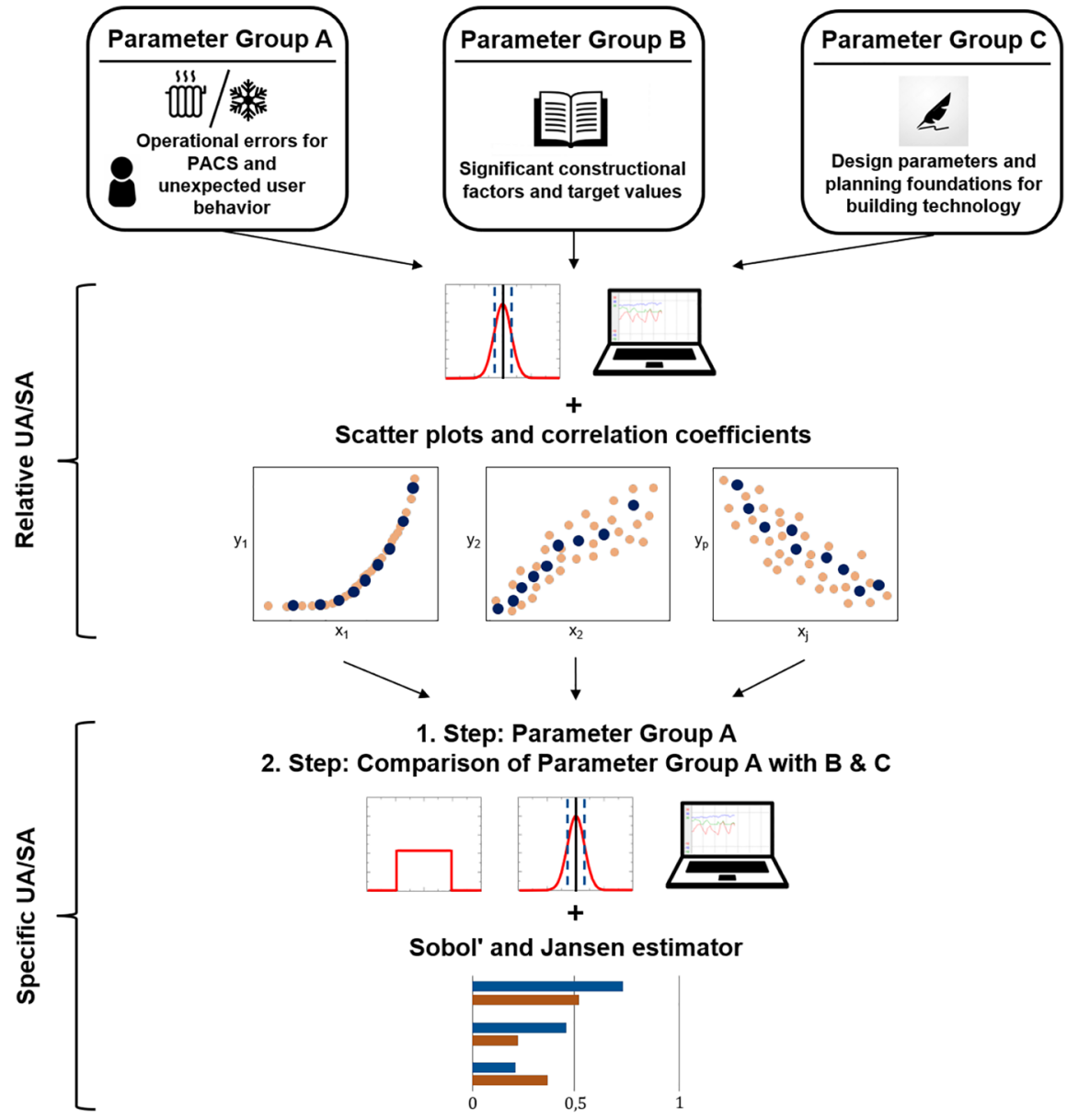

introduced by Saltelli (Saltelli, 2002) and Jansen (Jansen, 1999), which differentiates between a direct influence of the input variable on the target variable (main effect) and interaction effects between the input parameters (total effect). Both the main and total effects are between the interval $[0 ; 1]$ and can be calculated employing Eqs. (1) and (2) below for a sample-based method. The Sobol' estimator $\left(\widehat{\mathrm{S}}_{\mathrm{T}_{\mathrm{i}} \text {,Sobol }}\right)$ is used to calculate the main effect and the Jansen estimator $\left(\widehat{\mathrm{S}}_{\mathrm{T}_{\mathrm{i}}, \mathrm{Jansen}}\right)$ establishes the total effect. A high value indicates a great influence of the input variable on the target variable; for more on Sobol' and Jansen estimators, see (Campolongo et al., 2011) and (Saltelli \& Annoni, 2010). In this simulation step, applying the specific UA/SA, the probability distributions and the value ranges are selected for each input variable.

$$
\begin{aligned}
& \widehat{\mathrm{S}}_{\mathrm{T}_{\mathrm{i}} \text {, Sobol }}=1-\frac{\frac{1}{\mathrm{~N}-1} \times \sum_{\mathrm{r}=1}^{\mathrm{N}} \mathrm{f}_{\mathrm{A}, \mathrm{r}} \times\left[\mathrm{f}_{\mathrm{A}_{\mathrm{B}}^{(\mathrm{i})}, \mathrm{r}}-\mathrm{f}_{\mathrm{B}, \mathrm{r}}\right]}{\frac{1}{2 \mathrm{~N}-1} \times \sum_{\mathrm{r}=1}^{2 \mathrm{~N}}\left(\mathrm{f}_{\mathrm{AB}, \mathrm{r}}-\frac{1}{2 \mathrm{~N}} \sum_{\mathrm{r}=1}^{2 \mathrm{~N}} \mathrm{f}_{\mathrm{AB}, \mathrm{r}}\right)^{2}} \\
& \widehat{\mathrm{S}}_{\mathrm{T}_{\mathrm{i}}, \text { Jansen }}=\frac{\frac{1}{2 \mathrm{~N}} \times \sum_{\mathrm{r}=1}^{\mathrm{N}}\left(\mathrm{f}_{\mathrm{A}, \mathrm{r}}-\mathrm{f}_{\left.\mathrm{A}_{\mathrm{B}}^{(\mathrm{i}, \mathrm{r}}\right)^{2}}\right.}{\frac{1}{2 \mathrm{~N}-1} \times \sum_{\mathrm{r}=1}^{2 \mathrm{~N}}\left(\mathrm{f}_{\mathrm{AB}, \mathrm{r}}-\frac{1}{2 \mathrm{~N}} \sum_{\mathrm{r}=1}^{2 \mathrm{~N}} \mathrm{f}_{\mathrm{AB}, \mathrm{r}}\right)^{2}}
\end{aligned}
$$

The Sobol' and Jansen estimators are computationally intensive and can therefore only be used for a limited number of input parameters. Using the estimators requires a pre-selection process for all parameter groups, which is carried out as part of a relative UA/SA. Important parameters are identified here using scatter plots and correlation coefficients, which require a significantly smaller sample size but are also 
less accurate. The identical probability distribution with the same relative value range is selected for all parameters. In Fig. 2, the overall research methodology is summarized.

\section{Case study}

In this section, we describe a multi-stage MonteCarlo simulation process where operational errors in PACS as well as unexpected user behavior are examined and compared with construction factors. In addition to the model input uncertainty determined with MCS, the most significant input parameters are identified as part of sensitivity analyses. Due to the fact that PACS are often installed in office buildings to provide a high level of thermal comfort for users as well as to meet requirements for productivity factors, we investigate the building type "office buildings." The commercial software "IDA Indoor Climate and Energy (IDA ICE)" (IDA ICE, 2019) was used to model the building and HVAC systems. The MCSs were run simultaneously on a commercial workstation (Intel Xeon CPU E5-2650 2.00 GHz) with eight cores. An energy standard that requires a certain degree of automation for the investigated object was selected; therefore, the heat transfer coefficients of the building envelope in our study are based on (DIN, EN 15232, 2017) as well as (EnEV., 2007) and are summarized in Table 1.

The PACS is controlled by the exhaust air temperature (see Fig. 3: temperature controller 5.19) and supplies the zones with constant air volume (CAV) flow. According to Werner et al. (2008), in office buildings, PACS are more prevalent than full air conditioning systems; this in turn means that the simulation model contains the following components: a heat exchanger for heat recovery, a pre-heating coil as well as a postheating coil (for dehumidification purposes), and a cooling coil (see Fig. 3). The fans in the PACS delivers a total volume flow of $3320 \mathrm{~m}^{3} / \mathrm{h}$ for the air supply
Table 1 Building physics and user parameters according to DIN, EN 15232 (2017) and (EnEV., 2007)

Fig. 3 Partial air conditioning systems (PACS)

\begin{tabular}{llll}
\hline Parameter category & Parameter & Value & Unit \\
\hline Building physics parameters & U value external wall & 0.35 & $\mathrm{~W} /\left(\mathrm{m}^{2} \mathrm{~K}\right)$ \\
& U value roof & 0.25 & $\mathrm{~W} /\left(\mathrm{m}^{2} \mathrm{~K}\right)$ \\
& U value baseplate & 0.40 & $\mathrm{~W} /\left(\mathrm{m}^{2} \mathrm{~K}\right)$ \\
& U value window & 1.10 & $\mathrm{~W} /\left(\mathrm{m}^{2} \mathrm{~K}\right)$ \\
& Lighting & 13 & $\mathrm{~W} / \mathrm{m}^{2}$ \\
& & 120 & $\mathrm{~lm} / \mathrm{W}$ \\
User parameters & Illuminance level & $500 / 200 / 100$ & $1 \mathrm{x}$ \\
& Internal loads & 100 & $\mathrm{~W} /$ person \\
& Usage time & $5: 00-18: 00$ & $\mathrm{o}$ clock \\
\hline
\end{tabular}

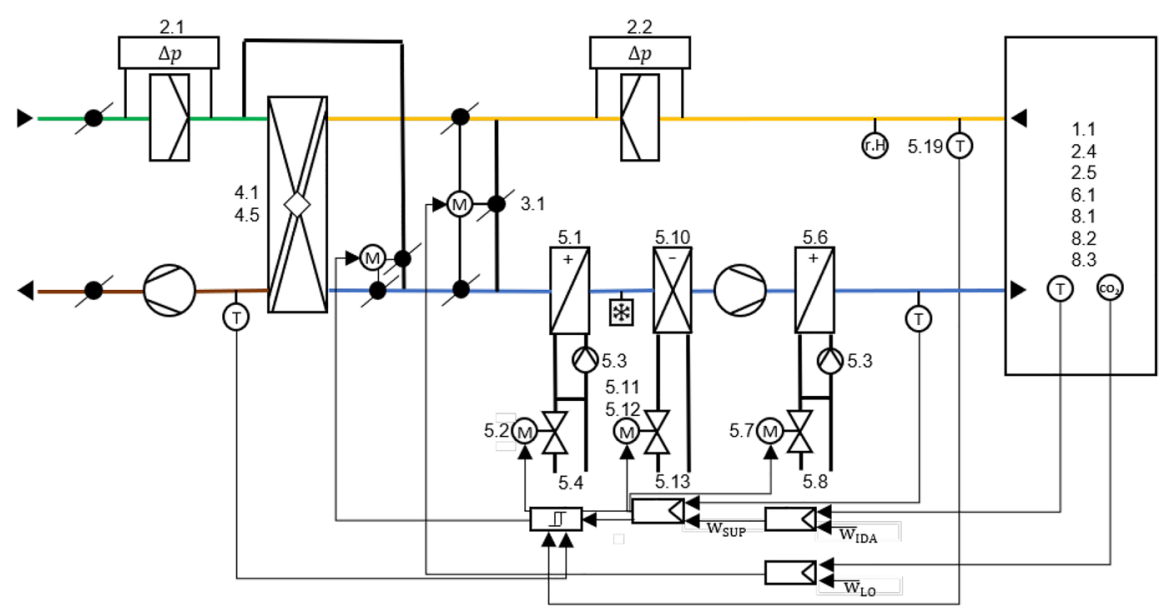


as well as the exhaust air, meaning that $40 \mathrm{~m}^{3} / \mathrm{h}$ is available for every person (DIN, V 18599-10, 2018).

A gas condensing boiler in combination with radiators provides the thermal energy for space heating. The supply of cold water for the cooling register of the PACS is ensured by a compression refrigerator. The following Table 2 shows the input parameters for building technology which are divided into controlled values and installation performance values.

The PED in $\mathrm{kWh} /\left(\mathrm{m}^{2} \mathrm{a}\right)$, as well as the thermal comfort, will be used as the output signal ("target variable"). The thermal comfort in $\mathrm{Kh} / \mathrm{a}$ is evaluated based on thermal comfort valuations defined in DIN, EN 15251 (2012) and calculated using Eqs. (3) and (4) below. The target variables for thermal comfort are divided between overheating hours $(\mathrm{OHH})$ and underheating hours (UHH). The current German primary energy factors are used to evaluate the PED. The standard defines a factor of 1.1 for electricity and 1.8 for natural gas for the non-renewable portion (DIN, V 18599-1, 2018).

$$
\begin{aligned}
& \mathrm{OHH}=\sum\left|\mathrm{T}_{\text {op }}-26\right| \cdot \mathrm{t}\left(\mathrm{T}_{\mathrm{op}}>\mathrm{T}_{\text {op_upper }}\right) \\
& \mathrm{UHH}=\sum\left|\mathrm{T}_{\mathrm{op}}-21\right| \cdot \mathrm{t}\left(\mathrm{T}_{\mathrm{op}}<\mathrm{T}_{\text {op_lower }}\right)
\end{aligned}
$$

For the base case and reference scenario with the boundary conditions in line with Tables 1 and 2, we obtained a specific PED of $92.9 \mathrm{kWh} /\left(\mathrm{m}^{2} \mathrm{a}\right)$, at $100.4 \mathrm{Kh} / \mathrm{a} \mathrm{OHH}$ and $140.9 \mathrm{Kh} / \mathrm{a} \mathrm{UHH}$ in IDAICE. These results are based on a point simulation (a classical simulation approach without MCS) and serve as a benchmark for further simulations with uncertain boundary conditions. To implement uncertainty and sensitivity analyses, the software R (R Core Team, 2018) is used for pre- and post-processing (see Fig. 1). For the relative analysis, a normal distribution (abbreviated as $\sim N$ ) of $\pm 5 \%$ standard deviation was selected as the probability distribution, based on (Hopfe \& Hensen, 2011) and (Ioannou, 2015). The analysis differentiated between relevant and less significant parameters. The standard deviation was also chosen because of numerical stability, which must be taken into account with a large number of input variables. A uniform standard deviation ensures that all parameters are equally weighted and make methodological sense, which is important since for a large number of parameters there are no measurement results that can be used to select the probability distributions and the value ranges (Table 3 ).

The second step of the workflow is the specific UA/SA, where probability distributions and value ranges for each input parameter are chosen parameter-dependent and adapted to real conditions (see Table 4). The number of input parameters is significantly reduced compared to the relative analysis. For a large number of the factors in the parameter groups $\mathrm{B}$ and $\mathrm{C}$, the distribution can be assigned on the basis of measurements and normative foundations (Table 4). Other input parameters are operational and user errors of parameter group A, which are mapped using the same distribution with the exception of error 5.19-exhaust air temperature sensor offset and

\begin{tabular}{|c|c|c|c|c|}
\hline Parameter category & Parameter & Value & Unit & References \\
\hline \multirow[t]{7}{*}{ Controlled values } & Minimum room air temperature setpoint & 21 & ${ }^{\circ} \mathrm{C}$ & (DIN, V 18599-10, 2018) \\
\hline & Maximum room air temperature setpoint & 24 & ${ }^{\circ} \mathrm{C}$ & (DIN, V 18599-10, 2018) \\
\hline & Temperature reduction outside of usage time & 4 & $\mathrm{~K}$ & (DIN, V 18599-10, 2018) \\
\hline & $\begin{array}{l}\text { Minimum temperature setpoint for exhaust air } \\
\text { (protection against icing) }\end{array}$ & 3 & ${ }^{\circ} \mathrm{C}$ & (Siemens, 2018) \\
\hline & Hot water temperatures for heating registers & $70 / 55$ & ${ }^{\circ} \mathrm{C}$ & (DIN, V 18599-7, 2016) \\
\hline & Setpoint range for the relative humidity in the zones & $25-60$ & $\%$ & (DIN, EN 16798-1, 2015) \\
\hline & $\begin{array}{l}\text { Maximum } \mathrm{CO}_{2} \text { content above the outside air con- } \\
\text { centration }\end{array}$ & 500 & ppm & (DIN, EN 16798-1, 2015) \\
\hline \multirow[t]{3}{*}{ Installation performance values } & Efficiency heat recovery coefficient & 75 & $\%$ & (Schramek \& Recknagel, 2011) \\
\hline & Gas boiler efficiency & 89 & $\%$ & (Schramek \& Recknagel, 2011) \\
\hline & EER compression chiller & 3 & - & (Schramek \& Recknagel, 2011) \\
\hline
\end{tabular}

Table 2 Input parameters for building technology (controlled and installation performance values) 
Table 3 Input variables of parameter group A for the relative UA/SA

\begin{tabular}{|c|c|c|}
\hline Name and brief description & Unit & Distribution \\
\hline Error $1.1-$ volume flow zone level & $1 /\left(\mathrm{sm}^{2}\right)$ & $\sim N(1.238 ; 0.062)$ \\
\hline Error 2.1 - differential pressure supply air fan & $\mathrm{Pa}$ & $\sim N(600.0 ; 30.0)$ \\
\hline Error 2.2-differential pressure exhaust air fan & $\mathrm{Pa}$ & $\sim N(500.0 ; 25.0)$ \\
\hline Error 2.4-start of operation of partial air conditioning system & o'clock & $\sim N(05: 00 ; 0.650)$ \\
\hline Error 2.5-termination of partial air conditioning system & o'clock & $\sim N(18: 00 ; 0.650)$ \\
\hline Error 3.1 -adjustment range of the air recirculation flap & - & $\sim N(0.000 ; 0.053)$ \\
\hline Error 4.1 -blocking temperature heat recovery & ${ }^{\circ} \mathrm{C}$ & $\sim N(3.000 ; 0.150)$ \\
\hline Error 4.5 - heat number of the heat recovery & - & $\sim N(0.750 ; 0.038)$ \\
\hline Error 5.1 -heat transfer pre-heating register & - & $\sim N(1.000 ; 0.050)$ \\
\hline Error 5.2 - control valve pre-heating register & $\mathrm{kg} / \mathrm{s}$ & $\sim N(0.000 ; 0.009)$ \\
\hline Error 5.3 - pump pre- and post-heating register & $\mathrm{Pa}$ & $\sim N(30000.0 ; 1500.0)$ \\
\hline Error 5.4-temperature spread pre-heating register & ${ }^{\circ} \mathrm{C}$ & $\sim N(15.000 ; 0.750)$ \\
\hline Error 5.6-heat transfer post-heating register & - & $\sim N(1.000 ; 0.050)$ \\
\hline Error 5.7-control valve post-heating register & $\mathrm{kg} / \mathrm{s}$ & $\sim N(0.000 ; 0.009)$ \\
\hline Error 5.8-temperature spread post-heating register & ${ }^{\circ} \mathrm{C}$ & $\sim N(15.000 ; 0.750)$ \\
\hline Error 5.10 - heat transfer cooling register & - & $\sim N(1.000 ; 0.050)$ \\
\hline Error $5.11-$ control valve cooling register & $\mathrm{kg} / \mathrm{s}$ & $\sim N(0.000 ; 0.018)$ \\
\hline Error 5.12 - pump cooling register & $\mathrm{Pa}$ & $\sim N(30000.0 ; 1500.0)$ \\
\hline Error 5.13-temperature spread cooling register & ${ }^{\circ} \mathrm{C}$ & $\sim N(6.0 ; 0.3)$ \\
\hline Error 5.19—exhaust air temperature sensor offset & ${ }^{\circ} \mathrm{C}$ & $\sim N(0.000 ; 1.080)$ \\
\hline Error 6.1 -humidity sensor offset & $\%$ & $\sim N(0.000 ; 1.701)$ \\
\hline Error 8.1 -number of people & - & $\sim N(2.0 ; 0.1)$ \\
\hline Error 8.2 -sun protection & $\mathrm{W} / \mathrm{m}^{2}$ & $\sim N(200.0 ; 10.0)$ \\
\hline Error 8.3-window opening time & h/day & $\sim N(0.000 ; 0.550)$ \\
\hline
\end{tabular}

Table 4 Input variables for the specific UA/SA

\begin{tabular}{|c|c|c|c|c|c|}
\hline Name and brief description (parameter group) & Unit & Distribution & Step 1 & Step 2 & References \\
\hline Error 1.1 -volume flow zone level (A) & $1 /\left(\mathrm{sm}^{2}\right)$ & $\sim U(0.000 ; 1.609)$ & $X$ & - & - \\
\hline Error 2.1 - differential pressure supply air fan (A) & $\mathrm{Pa}$ & $\sim U(0.0 ; 700.0)$ & $\mathrm{X}$ & - & - \\
\hline $\begin{array}{l}\text { Error } 2.5 \text {-termination of partial air conditioning } \\
\text { system (A) }\end{array}$ & o'clock & $\sim U(05: 00 ; 24: 00)$ & $\mathrm{X}$ & $\mathrm{X}$ & - \\
\hline $\begin{array}{l}\text { Error } 5.8 \text { - temperature spread post-heating register } \\
\text { (A) }\end{array}$ & ${ }^{\circ} \mathrm{C}$ & $\sim U(0.1 ; 50.0)$ & $X$ & - & - \\
\hline Error 5.19-exhaust air temperature sensor offset (A) & ${ }^{\circ} \mathrm{C}$ & $\sim N(0.000 ; 0.970)$ & $X$ & - & (Brohus \& Heiselberg, 2009) \\
\hline Error 8.1 -number of people (A) & - & $\sim N(2.0 ; 1.0)$ & $\mathrm{X}$ & $\mathrm{X}$ & (Macdonald, 2002) \\
\hline Error $8.2-$ sun protection (A) & $\mathrm{W} / \mathrm{m}^{2}$ & $\sim U(0.0 ; 1000.0)$ & $\mathrm{X}$ & $\mathrm{X}$ & (Kaltschmitt et al., 2013) \\
\hline Error 8.3 -window opening time (A) & h/day & $\sim U(0.0 ; 0.25)$ & $X$ & $X$ & (Osterhage, 2018) \\
\hline Minimum room air temperature setpoint (B) & ${ }^{\circ} \mathrm{C}$ & $\sim N(21.000 ; 0.970)$ & - & $\mathrm{X}$ & (Brohus \& Heiselberg, 2009) \\
\hline Maximum room air temperature setpoint (B) & ${ }^{\circ} \mathrm{C}$ & $\sim N(24.000 ; 0.970)$ & - & $\mathrm{X}$ & (Brohus \& Heiselberg, 2009) \\
\hline Gas boiler efficiency $(\mathrm{C})$ & - & $\sim U(0.880 ; 0.990)$ & - & $X$ & (Schramek \& Recknagel, 2011) \\
\hline Plant engineering (start of operation) (C) & o'clock & $\sim U(03: 00 ; 05: 00)$ & - & $X$ & (DIN, V 18599-10, 2018) \\
\hline Plant engineering (end of operation) (C) & o'clock & $\sim U(18: 00 ; 21: 00)$ & - & $X$ & $\begin{array}{l}\text { (DIN, V 18599-10, 2018; Li \& } \\
\text { O’Neill, 2018) }\end{array}$ \\
\hline Flow temperature cooling register $(\mathrm{C})$ & ${ }^{\circ} \mathrm{C}$ & $\sim \mathrm{U}(6.0 ; 14.0)$ & - & $\mathrm{X}$ & (DIN, V 18599-7, 2016) \\
\hline
\end{tabular}


error 8.1-number of people per zone. According to Brohus and Heiselberg (2009) and (Macdonald, 2002), these two input variables were mapped with a normal distribution. The value range of the equally distributed error states (abbreviated as $\sim U$ ) fluctuates between 0 and $100 \%$, i.e., within physical limits. We assume that these conditions can also occur in real systems, which is why we consider the range of values to be meaningful. The probability distributions and value ranges enable us to compare operational and user errors in PACS (which represents parameter group A) and parameter groups B and C.

\section{Results and discussion}

Specific UA/SA—step 1: parameter group A

The probability distributions and value ranges of the specific UA/SA are shown in Table 4. In total, eight operational and user errors have proven to be significant in the relative UA/SA and are examined in the following specific UA/SA. This investigation was carried out in two steps: the first step only includes parameter group $\mathrm{A}$, and the second one compares the most significant input variables of all parameter groups (A, B, C). The results are based on a sampling of Sobol' sequences with 1200 runs (step 1) and 1440 runs (step 2). In this context, the sample size of 1024 or 2048 would have been better for the performance of the Sobol' sequences $\left(N=2^{\mathrm{j}}\right.$ where $\mathrm{j} \in \mathbb{N}^{+}$), but due to the restrictive requirements for the application of the sensitivity index "Conditional Variances-Second Path," these numbers were selected. We chose the method of Sobol' sequences because it generates samples which are distributed as evenly as possible in the multidimensional parameter space. In this process, the random numbers were chosen taking into account the numbers already drawn in order to prevent accumulations and gaps in the parameter space. As a result, the MCS converged faster than when using other methods to draw samples, which is why the Sobol' sequences show good convergence behavior in building simulations according to Burhenne et al. (2011) and (Maderspacher, 2017) and are commonly used in this field. The sensitivity analyses are carried out with different methods as previously explained. Besides the correlation coefficients and the Sobol' and Jansen estimators, we employed a third method, scatter plots. To enable a ranking of the parameters with this technique, the method "Conditional Variances-Second Path" was applied. First, the $\mathrm{x}_{\mathrm{i}}$ range is divided into 10 parts, with each part receiving the same number of points; then, the mean of the output $y_{i}$ is calculated in each part and the variance of the means of all 10 parts is calculated. Finally, the calculated variance is a sensitivity index; the higher the variance, the greater the sensitivity. Due to the restrictive requirements for the application of the "Conditional Variances-Second Path" method, a sampling size of 120 (instead of $2^{7}=128$ ) was selected.

In Fig. 4 below, the results of all simulations for the target figure primary energy demand, over- and under-temperature degree hours are presented in postprocessing on the basis of graphic evaluation methods using histograms and box plots. Furthermore, the histograms show the probability density function with the median (black dotted line) as well as the first and third quartile (blue dotted line).

The histogram of the target figure primary energy demand shows a left skewed distribution with a median of $72.6 \mathrm{kWh} /\left(\mathrm{m}^{2} \mathrm{a}\right)$. At first glance, the result does not seem to be logical because the median is well below the reference scenario (base case PED $\left.92.9 \mathrm{kWh} /\left(\mathrm{m}^{2} \mathrm{a}\right)\right)$. The discrepancy and reduction of the PED can be explained by the differences between the calculation methods in terms of point simulation (base case) and MCS. However, the median for both the over- and under-temperature degree hours is above the reference scenario. Consequently, the reduction in primary energy demand decreases thermal comfort. Overall, the influence of parameter group A is particularly strong for the UHH. Surprisingly, the median values of the $\mathrm{OHH}$ and the $\mathrm{UHH}$ are almost identical, though the quartiles of the UHH show greater deviations. With a probability of $50 \%$, the quartiles range between 106.3 Kh/a and 289.2 Kh/a. For the OHH, a maximum value of $217.3 \mathrm{Kh} / \mathrm{a}$ was calculated, which means that the threshold of $500 \mathrm{Kh} / \mathrm{a}$ (DIN, 4108-2, 2013) for non-residential buildings is not reached. This in turn means that the operational and user errors are not critical for thermal overheating of the building.

The main and total effects of the specific SA of parameter group A are shown in Fig. 5 below: the greater value of an input parameter signifies a greater influence on the target variable. 
Fig. 4 Specific UA of parameter group A (top to bottom: PED, $\mathrm{OHH}$, and $\mathrm{UHH})$
Fig. 5 Total and main effects of the specific SA of parameter group A
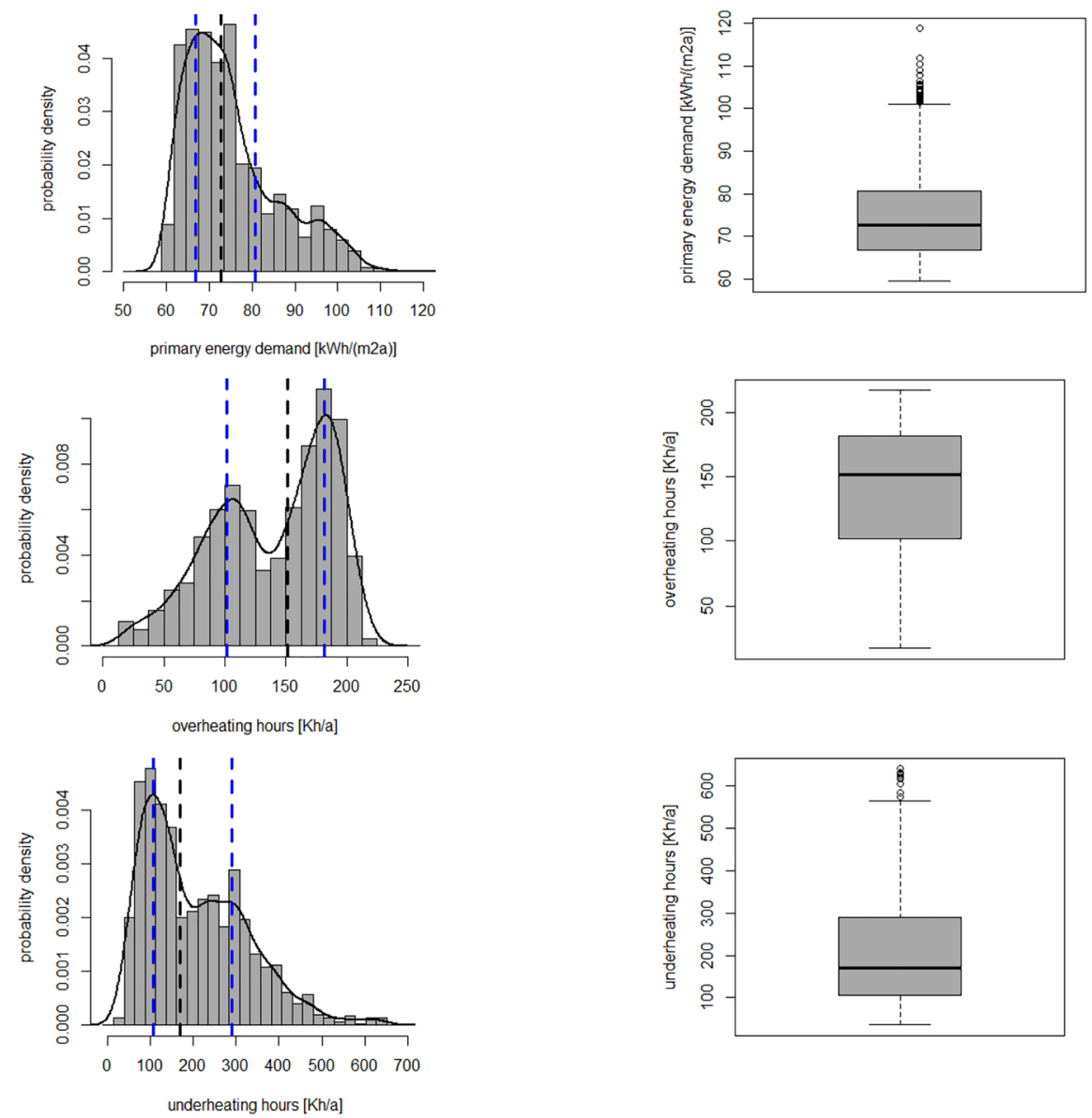

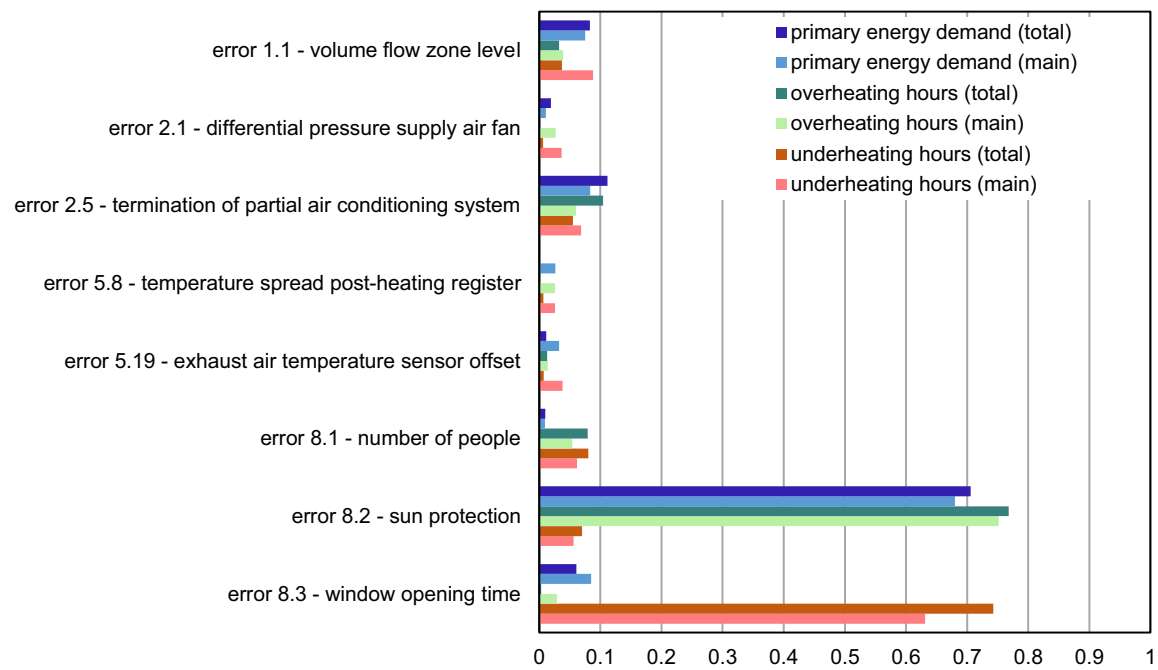

If the total effects of the two most influential variables of each target variable are added, the result is $0.71+0.11=0.82$ for the PED (1. error 8.2-sun protection/2. error 2.5-termination of partial air conditioning system), $0.77+0.10=0.87$ (1. error 8.2-sun protection/2. error 2.5-termination of 
partial air conditioning system) for the $\mathrm{OHH}$, and $0.74+0.08=0.82$ (1. error 8.3-window opening time/2. error 8.1-number of people) for the UHH. Consequently $82 / 87 / 82 \%$ of model input uncertainty is caused by the two most important input variables. In each category, both the main and the total effect are dominated by one parameter; the user error $8.2-$ sun protection influences the PED with a main effect of $68 \%$ and the $\mathrm{OHH}$ with $75 \%$. The error 8.3 -window opening time shows a main effect of $63 \%$ on the UHH. The influence of operational errors is less than the influence of the user errors on the target values. If the total effects of all operational errors of each target variable are added together, the effect on PED is $22 \%$, for $\mathrm{OHH} 14 \%$, and for UHH $12 \%$. In this context, the error 2.5-termination of partial air conditioning system should be highlighted as a high impact operational error, which is second in the importance for the total effects on PED and $\mathrm{OHH}$, as well as third for UHH.

Specific UA/SA — step 2: comparison of parameter group $\mathrm{A}$ with $\mathrm{B}$ and $\mathrm{C}$

For all three target values, Fig. 6 contains the histograms and the box plots as part of the statistical evaluation in post-processing. The characteristic understanding of the logarithmic normal distribution is the flat descent on one side. It follows that there is a limit in the value range for all target variables, which increase significantly for unfavorable combinations of the input parameters.

For the PED, the median and the upper and lower quartile are positioned in a dense area (Fig. 6). The values for the $\mathrm{OHH}$ are with a high probability in a comfortable range from $88.2 \mathrm{Kh} / \mathrm{a}$ to $199.8 \mathrm{Kh} / \mathrm{a}$,
Fig. 6 Specific UA of parameter groups A, B, and $\mathrm{C}$ (top to bottom: PED, $\mathrm{OHH}$, and $\mathrm{UHH}$ )
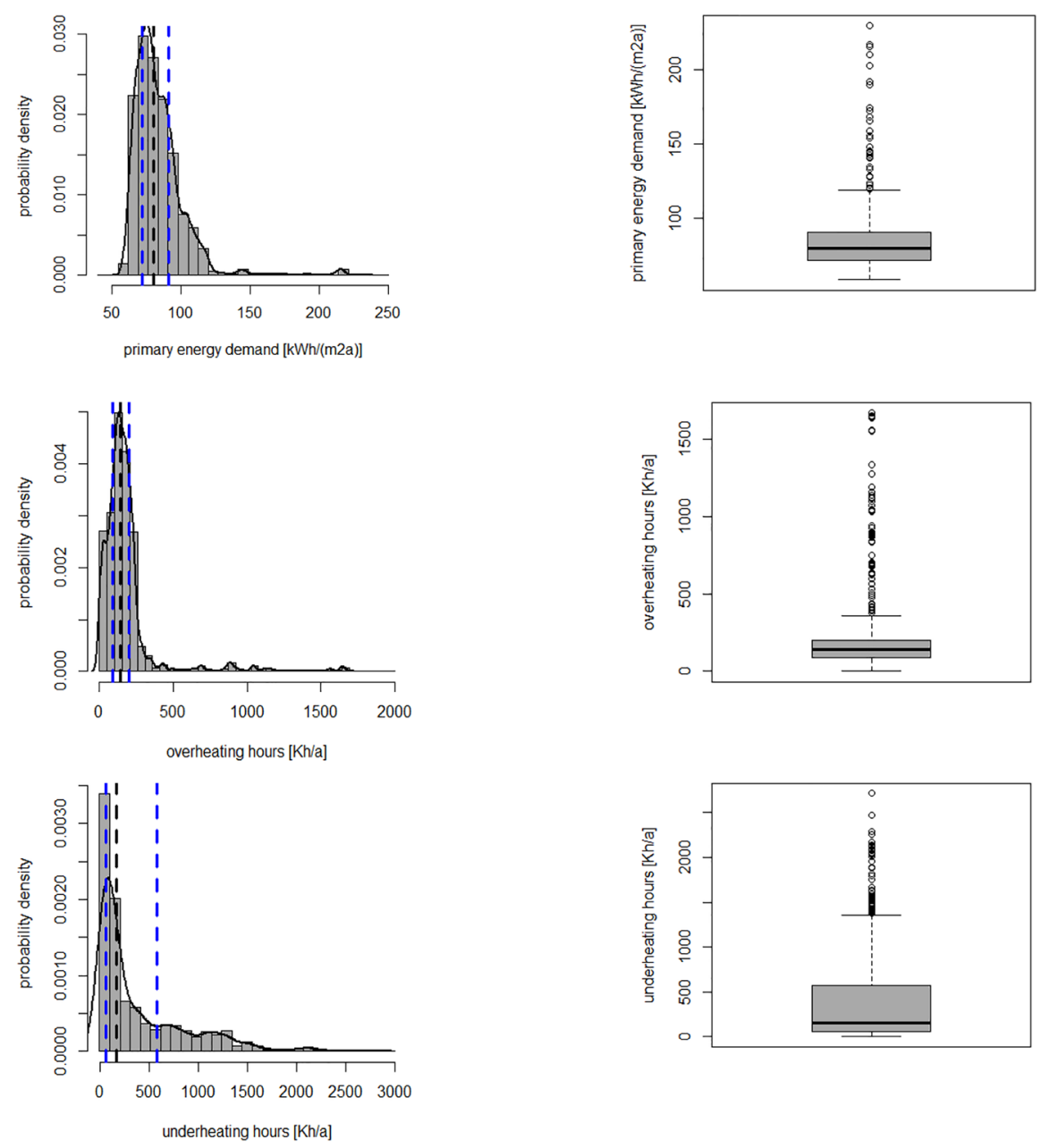
but reach up to a maximum of $1668.8 \mathrm{Kh} / \mathrm{a}$ for unfavorable parameter combinations. The medians of the $\mathrm{OHH}$ and $\mathrm{UHH}$ are close, but the distance from the quartiles is significantly higher than for the UHH.

Figure 7 shows the total and main effects of the specific SA of parameter groups A, B, and C. Adding the total effects of the three most influential variables for each target variable results in $87 \%$ for the PED ( 1 . min. room air temperature setpoint/2. max. room air temperature setpoint/3. error 8.2-sun protection), $98 \%$ for the $\mathrm{OHH}$ (1. max. room air temperature setpoint/2. error 8.2-sun protection error/3. error 8.1 - number of people), and $95 \%$ for the UHH ( 1 . min. room air temperature setpoint/2. error 8.2-sun protection/3. error 8.3-window opening time). The parameters min. room air temperature setpoint and max. room air temperature setpoint followed by error 8.2 - sun protection have the greatest influence on PED which is based on the total effects. The strong influence of the temperature setpoints on the PED can be justified by the choice of the value ranges found in Brohus and Heiselberg (2009). Both parameters are subject to a standard deviation of 0.97 . For unfavorable parameter combinations, the maximum temperature setpoint can reach below the minimum setpoint, so the building is heated and cooled at the same time. For the main effect, error 8.2-sun protection has the greatest significance on the PED. In this case, the influence of the temperature setpoints is weaker. Accordingly, these two parameters are strongly influenced by interaction effects. In the context of parameter group A, error 2.5-termination of partial air conditioning system, with a main effect of 0.09 and a total effect of 0.11 , is the second most important factor affecting the PED, meaning it is the most important factor for the energy efficient operation of PACS. The $\mathrm{OHH}$ are determined by the parameter max. room air temperature setpoint and have a total effect of $89 \%$. Error 8.2-sun protection is considerably less significant at $7 \%$. When the value ranges of the parameters are analyzed, the difference is as follows: the parameter max. room air temperature setpoint reaches, due to the defined expected value, $24{ }^{\circ} \mathrm{C}$ and a defined standard deviation of 0.97 random samples which are greater than $26{ }^{\circ} \mathrm{C}$. The room air temperature of the zones is therefore only cooled by a temperature value that has already exceeded the threshold for thermal overheating, according to DIN, 4108-2, (2013), which is reflected in the significance of the main and total effects for this parameter. With $84 \%$ (main effect) and 86\% (total effect), the min. room air temperature setpoint has the greatest importance for the UHH. Analogous to the max. room air temperature setpoint, the high significance of the input is revealed when the samples fall below the defined threshold value for the UHH evaluation. In general,
Fig. 7 Total and main effects of the specific SA of parameter groups A, B \& C

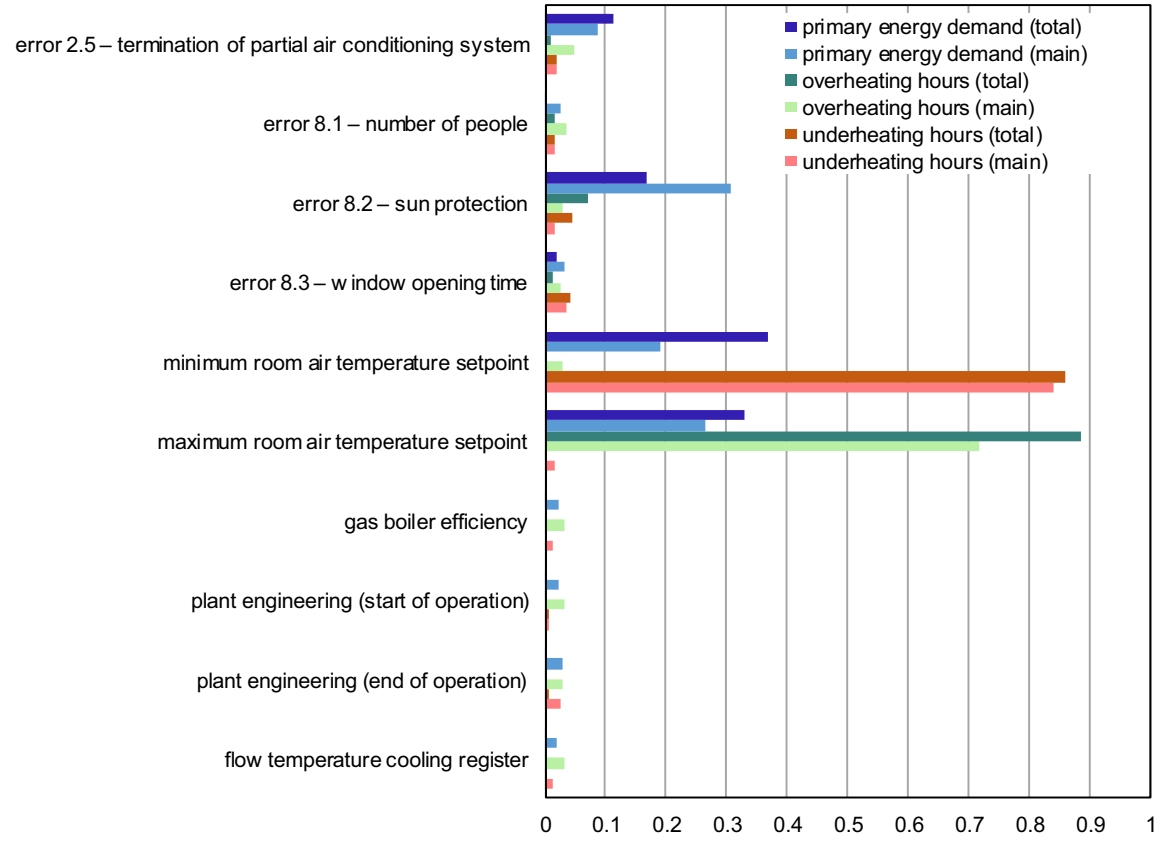


there are just small differences between the main and total effects for the UHH, so the interaction effects in this category can be classified as small.

\section{Conclusion and outlook}

\section{Conclusion}

Resource scarcity and anthropogenic climate change are one of the main global challenges. To reach the climate protection targets, performance gaps must be reduced in existing buildings. The main drivers for performance gaps are unexpected user behaviors and operational errors in building technology. With the applied research methodology, we have identified the most relevant operational and user errors for PACS in office buildings, and calculated the model input uncertainty for the target values of primary energy demand, over- and under-temperature degree hours. All inputs were classified in three different parameter groups, and the analyses of group A showed that operational and user errors cause the greatest model input uncertainty for UHH. The risk of thermal overheating plays a tangential role and is within the comfort range (DIN, 4108-2, 2013) even for the extreme values. Unexpectedly, the medians of the $\mathrm{OHH}$ and $\mathrm{UHH}$ have almost identical values, while the UHH quartiles have a higher deviation. The PED is subject to low model input uncertainty compared to the other target functions. Hence, most errors and error combinations appear to lead to only a small increase in the PED. An increase up to $118.7 \mathrm{kWh} /$ $\left(\mathrm{m}^{2} \mathrm{a}\right)$, and thus an increase of approx. 30\% compared to the base case with $92.9 \mathrm{kWh} /\left(\mathrm{m}^{2} \mathrm{a}\right)$, is only to be feared for unfavorable parameter combinations. Every target value is largely dominated by an operational and user error. The error 8.2-sun protection influences the PED with a main effect of $68 \%$ and the $\mathrm{OHH}$ with $75 \%$. The error 8.3 -window opening time has a main effect of $63 \%$ on the UHH. Based on our MCS results, the user errors have a greater impact on the target values than the operational errors. However, only some of the operational errors were examined in this paper. The comparison of the parameter groups in the context of the specific UA/SA showed that operational and user errors in PACS are important, but do not have the relevance of the min. room air temperature setpoint and max. room air temperature setpoint, which are in parameter group B. The number of $\mathrm{OHH}$ and UHH in particular is clearly determined by these two parameters. From parameter group A, the most sensitive operational error is 2.5-termination of partial air conditioning system with a total effect of $11 \%$ for the PED and the most important user error is 8.2 - sun protection with a total effect of $17 \%$ and $7 \%$ for the PED and the OHH. For all three target values, the histograms are similar to a logarithmic normal distribution. For very unfavorable parameter combinations, there is a risk of a sharp increase in the target values, but with a limit in the low value ranges. Overall, the significance of the simulation results was significantly increased by comparing the operational and user errors with the parameter groups B and C.

The results of our MCS and investigations with uncertainty and sensitivity analyses allow us to draw conclusions and valuations regarding other configurations of air handling units in general. Depending on the configuration, AHUs (ventilation-, partial air conditioning-, full air conditioning system) may have more or fewer components, so operational errors can be increased or reduced. For operational errors that can occur in other air handling units as well (e.g., error is 2.5-termination of partial air conditioning system), this in turn means a similar relevance can be assumed for this error scenario. This paper shows what potentials for building optimization in terms of increased energy efficiency and thermal comfort can be achieved with low investment. Our results should be relevant for building owners and/or operators as well as facility managers due to the fact that a reduction in energy consumption is followed by the reduction of operating costs and greenhouse gas emissions. Moreover, the relevant input variables should be the main focus of building operators to functionally test building technology in terms of increasing energy efficiency. These variables should also be incorporated by the major players involved in the planning process of buildings and their systems engineering.

Outlook

For the selection process in the context of the relative $\mathrm{UA} / \mathrm{SA}$, a normal distribution with $\pm 5 \%$ standard deviation was selected in order to weight all input variables equally. However, the procedure must also be critically examined. If samples are close to the physical limit for some parameters, significantly larger value ranges are 
possible for other input variables. A selection of relevant parameters based on individual probability distributions and value ranges should be investigated in the future. Moreover, the different sampling strategies should be compared and analyzed in terms of their convergence behavior as well as robustness for the building simulation model.

To improve the process of modeling operational errors, future research should be devoted to studying error characteristics in greater detail. In this paper, our approach was to give all input parameters the same probability of occurrence due to the fact that there are no long-term measurements or studies that deal with the frequency and intensity of operational errors in PACS. Our MCS run and analysis methods resulted in long computing times of up to 5 days; the simulation of operational errors on the basis of replacement models (mathematical substitute models) should reduce this long simulation time, which would make it possible to simulate more errors using the computationally intensive Sobol' and Jansen estimators.

With the operational errors in PACS, one discipline of building technology was examined in our research. As the case study shows, building technology systems can be efficiently examined with an MCS and the sensitivity analysis methods used here. Since the method is basically a generic approach, an expansion to further configurations of air conditioning systems and additional operational errors would be desirable and should be implemented in the future. For this purpose, we recommend incorporating construction factors and target values as they can be mapped in a thermo-dynamic building model with little effort, but would considerably increase the informative value of the outcome and its comparability in the overall context of investigation.

Acknowledgements The authors thank their managing editors for helping facilitate the joint publication of this commentary.

Funding Open Access funding enabled and organized by Projekt DEAL.

\section{Declarations}

Conflict of interest The authors declare no competing interests.

Open Access This article is licensed under a Creative Commons Attribution 4.0 International License, which permits use, sharing, adaptation, distribution and reproduction in any medium or format, as long as you give appropriate credit to the original author(s) and the source, provide a link to the Creative Commons licence, and indicate if changes were made. The images or other third party material in this article are included in the article's Creative Commons licence, unless indicated otherwise in a credit line to the material. If material is not included in the article's Creative Commons licence and your intended use is not permitted by statutory regulation or exceeds the permitted use, you will need to obtain permission directly from the copyright holder. To view a copy of this licence, visit http://creativecommons.org/licenses/by/4.0/.

\section{References}

Auer, T., Lauss, L., et al. (2020). Big Data in der Gebäudeautomation - Big Data Analysen von Automationsdaten zur energetischen Betriebsoptimierung des Gebäudebestandes, Research Report, Chair of Building Technology and Climate Responsive Design, Technical University Munich. https://doi.org/10.14459/2020m d1546757. Can be downloaded at: https://mediatum.ub. tum.de/doc/1546757/1546757.pdf

Brohus, H. \& Heiselberg, P. (2009). Uncertainty of energy consumption assessment of domestic buildings. Glasgow. Can be downloaded at: http://www.ibpsa.org/procee-dings/BS2009/BS09_1022_1029.pdf

Burhenne, S. (2013). Monte Carlo based uncertainty and sensitivity analysis for building performance simulation. p. 208, Can be ordered from: https://www.shaker. de, ISBN: 978-3-8440-2502-6

Burhenne, S., Jacob, D. \& Henze, G. (2011). Sampling based on Sobol' sequences for Monte Carlo techniques applied to building simulations. p. 1821, Can be downloaded at: https://www.researchgate.net/publication/257139589_ Sampling_based_on_Sobol\%27_sequences_for_Monte_ Carlo_techniques_applied_to_building_simulations

Campolongo, F., Saltelli, A., and Cariboni, J. (2011). From screening to quantitative sensitivity analysis. A unified approach. Computer Physics Communications, 182(4):978-988, Can be ordered from: https://www. sciencedirect.com

Corrado, V. \& Mechri, H. E. (2009). Uncertainty and sensitivity analysis for building energy rating. Can be ordered from: https://journals.sagepub.com/doi/10. $1177 / 1744259109104884$

Cox, D. C. \& Baybutt, P. (1981). Methods for uncertainty analysis: A comparative survey. Risk Analysis, 1(4), 251-258. Can be downloaded at: https://doi.org/10. 1111/j.1539-6924.1981.tb01425.x

DIN, 4108-2 (2013). Wärmeschutz und Energie-Einsparung in Gebäuden. Berlin: Beuth Verlag GmbH. p 28, Can be ordered from: https://www.beuth.de/

DIN, EN 15232 (2017). Energieeffizienz von Gebäuden. Berlin: Beuth Verlag GmbH. Can be ordered from: https:// www.beuth.de/

DIN, EN 15251 (2012). Eingangsparameter für das Raumklima zur Auslegung und Bewertung der Energieeffizienz von Gebäuden - Raumluftqualität, Temperatur, 
Licht und Akustik. Berlin: Beuth Verlag GmbH. Can be ordered from: https://www.beuth.de/

DIN, EN 16798-1 (2015). Gesamtenergieeffizienz von Gebäuden. Berlin: Beuth Verlag GmbH. p. 62, Can be ordered from: https://www.beuth.de/

DIN, V 18599-1 (2018). Energetische Bewertung von Gebäuden - Berechnung des Nutz-, End- und Primärenergiebedarfs für Heizung, Kühlung, Lüftung, Trinkwarmwasser und Beleuchtung - Teil 1: Allgemeine Bilanzierungsverfahren, Begriffe, Zonierung und Bewertung der Energieträger. Berlin: Beuth Verlag GmbH. p. 78, Can be ordered from: https://www.beuth.de/

DIN, V 18599-10 (2018). Energetische Bewertung von Gebäuden - Berechnung des Nutz-,End- und Primärenergiebedarfs für Heizung, Kühlung, Lüftung, Trinkwarmwasser und Beleuchtung - Teil 10: Nutzungsrandbedingungen, Klimadaten. Berlin: Beuth Verlag GmbH. Can be ordered from: https://www.beuth.de/

DIN, V 18599-7 (2016). Energetische Bewertung von Gebäuden - Berechnung des Nutz-,End- und Primärenergiebedarfs für Heizung, Kühlung, Lüftung, Trinkwarmwasser und Beleuchtung - Teil 7: Endenergiebedarf von Raumlufttechnik- und Klimakältesystemen für den Nichtwohnbau. Berlin: Beuth Verlag GmbH. Can be ordered from: https://www.beuth.de/

EnEV. (2007). Verordnung über energiesparenden Wärmeschutz und energiesparende Anlagentechnik bei Gebäuden (Energieeinsparverordnung - EnEV).

Fisch, N., Plesser, S. \& Bremer, C. (2007). EVA - Evaluierung von Energiekonzepten für Bürogebäude. Braunschweig. Can be ordered from: https://www.tu-braunschweig.de

Grob, R. F., Harter, J., Schmidt, M. \& Bach, H. (2002). COURAGE. Computergestuetzte Ueberpruefung von bestehenden heiz- und raumlufttechnischen Anlagen. Abschlussbericht, Stuttgart. Can be downloaded at: https://www.osti.gov/ etdeweb/biblio/20370321

Haves, P. (1997). Fault modelling in component-based HVAC simulation. Prague. Can be downloaded at: http://www. ibpsa.org/proceedings/BS1997/BS97_P101.pdf

Hopfe, C. \& Hensen, J. (2011). Uncertainty analysis in building performance simulation for design support. Eindhoven. 2798-2805. Can be downloaded at: https://www.researchga te.net/publication/258291390_Uncertainty_analysis_in_ building_performance_simulation_for_design_support

Hyvärinen, J. (1996). Building optimization and fault diagnosis source book (International Energy Agency energy conservation in buildings and community systems programme Real time simulation of HVAC systems for building optimization, fault detection and diagnosis, Report Vol. 1). Espoo: VTT Building Technology.

(2019). IDA ICE (Version 4.8) [Computer software]. Zug: EQUA Simulation AB. Can be ordered from: https://www.equa.se/ de

Ioannou, A. (2015). Energy performance and comfort in residential buildings: Sensitivity for building parameters and occupancy. Delft. Energy and Buildings, 92, 216-233. Can be downloaded at: https://doi.org/10.1016/j.enbuild.2015.01. 055

Jansen, M. J. (1999). Analysis of variance designs for model output. Computer Physics Communications, 117 (1-2), p. 35-43, Can be downloaded at: https://doi.org/10.1016/ S0010-4655(98)00154-4
Kaltschmitt, M., Streicher, W. \& Wiese, A. (2013). Erneuerbare Energien. Berlin, Heidelberg: Springer Berlin Heidelberg. p. 73, Can be downloaded at: https://doi.org/10.1007/ 978-3-642-03249-3

Lauss, L., Mehnert, J., et al. (2020). Energieeffizienz durch BigData-Analysen in der Gebäudeautomation. IBPSA Germany and Austria, Conference Proceeding BauSIM2020, 161-169. https://doi.org/10.3217/978-3-85125-786-1, Can be downloaded at: https://diglib.tugraz.at/download.php? $\mathrm{id}=5$ f8eb9e 21 ef6c\&location=browse

Li, Y. \& O'Neill, Z. (2018). A critical review of fault modeling of HVAC systems in buildings. Tuscaloosa. p. 956, Can be ordered from: https://www.springerprofessional.de/a-criti cal-review-of-fault-modeling-of-hvac-systems-in-buildings/ 15955068

Macdonald, I. A. (2002). Quantifying the effects of uncertainty in building simulation. Strathclyde. p. 106, Can be downloaded at: https://www.researchgate.net/publication/26007 9825_Quantifying_the_Effects_of_Uncertainty_in_Build ing_Simulation

Maderspacher, J. (2017). Robuste Optimierung in der Gebäudesimulation. p. 70, Can be ordered from: https://mediatum.ub. tum.de/

Mojic, I., Luzzatto, M., Haller, M., Lehmann, M., Benz, M. \& van Velsen, S. (2018). ImmoGap. Einfluss der Kombination aus Nutzerverhalten und Gebäudetechnik auf den Performance Gap bei Mehrfamilienhäuser. Rapperswil. Can be downloaded at: https://www.minergie.ch/media/501469_ haller_sb_immogap.pdf

Osterhage, T. (2018). Messdatengestützte Analyse und Interpretation sanierungsbedingter Effizienzsteigerungen im Wohnungsbau. Dortmund. p. 116, Can be downloaded at: https:// eldorado.tu-dortmund.de/handle/2003/37820

R Core Team. (2018). A language and environment for statistical computing. [Computer software]: R Foundation for Statistical Computing. Can be ordered from: https://www.r-project. org

Réhault, N. \& Zehnle, S. (2019). OBSERVE Arbeitspaket AP A.3. Modellbildung, Unsicherheitsbewertung, Sensitivitätsanalyse, Optimierung. Fribourg. Can be downloaded at: https:// www.ls.haw-hamburg.de/ ob-serve/wp-content/uploads/ APA3.pdf

Reimann, W. \& Bühlmann, E. (2016). Erfolgskontrolle Gebäudeenergiestandards 2014-2015. Bern. p. 92, Can be downloaded at: https://www.econcept.ch/de/projekte/erfolgskon trolle-gebaudeenergiestandards-2014-2015_0/

Saltelli, A. (2002). Making best use of model evaluations to compute sensitivity indices. Computer Physics Communications, 145 (2), p. 280-297, Can be downloaded at: https://doi.org/ 10.1016/S0010-4655(02)00280-1

Saltelli, A., Annoni, P. (2010). How to avoid a perfunctory sensitivity analysis. Environmental Modelling \& Software, 25(12):1508-1517, Can be ordered from: https://www.scien cedirect.com

Schramek, E.-R. \& Recknagel, H. (2011). Taschenbuch für Heizung und Klimatechnik 2011/2012. Einschließlich Warmwasser- und Kältetechnik. Can be ordered from: https:// www.beuth.de/

Siemens AG. (2018). Regeln und Steuern von Lüftungs-/ Klimaanlagen. Frankfurt. E10003-A38-H337. p. 41. 
Struck, C. (2014). „Performance gap“ in der Schweiz. Brisanz, Ursachen und Einflüsse auf die Differenz von geplantem Energiebedarf und gemessenem Verbrauch in Gebäuden. Zurich. p. 7, Can be downloaded at: https://www.researchga te.net/publication/265849849_Performance-Gap_in_der_ Schweiz_Brisanz_Ursachen_und_Einflusse_auf_die_Diffe renz_von_geplantem_Energiebedarf_und_gemessenen_ Energieverbrauch_in_Gebauden

Werner, P., Chmella-Emrich, E. \& Vilz, A. (2008). Folgen des Klimawandels: Gebäude und Baupraxis in Deutschland.
Berlin. 1863-8732. p. 21, Can be downloaded at: https:// dnb.info/988933985/34

Publisher's note Springer Nature remains neutral with regard to jurisdictional claims in published maps and institutional affiliations. 